\title{
A Novel ND3 Mitochondrial DNA Mutation in Three Korean Children With Basal Ganglia Lesions and Complex I Deficiency
}

\author{
JONG HEE CHAE, JIN SOOK LEE, KI JOONG KIM, YONG SEUNG HWANG, EDUARDO BONILLA, KURENAI TANJI, \\ AND MICHIO HIRANO
}

\author{
Department of Neurology [J.H.C., E.B., K.T., M.H.], Columbia University College of Physicians and Surgeons, New York, New York \\ 10032; Department of Pediatrics [J.H.C., J.S.L., K.J.K., Y.S.H.], Seoul National University College of Medicine, Seoul, Korea 110-744
}

\begin{abstract}
Mitochondrial disorders have notoriously variable clinical presentations, particularly in children. A growing number of reports describe mutations in the mitochondrial DNA (mtDNA)encoded subunits of complex I (EC 1.6.5.3) causing early-onset encephalopathy. Here, we describe two Korean siblings with childhood-onset progressive generalized dystonia and one Korean child with strokelike episodes in infancy; all three had bilateral lesions of the basal ganglia and partial deficiencies of complex I. Analysis of their mtDNA revealed a novel heteroplasmic m.10197G $>$ A mutation (A47T) in the ND3 (NADH dehydrogenase subunit 3) gene. This study underscores the importance of screening mtDNA-encoded respiratory chain structural genes, including ND3, in pediatric patients with unexplained encephalopathies. (Pediatr Res 61: 622-624, 2007)
\end{abstract}

$\mathrm{S}$ ince the identification of the first mtDNA point mutation in the ND4 gene of LHON patients (1), more than 100 mtDNA mutations in transfer RNA genes have been identified, but, over the past few years, increasing attention has been focused on mtDNA mutations in protein-coding genes. Point mutation in the ND1, ND3, ND4, ND5, and ND6 subunit genes of complex I have been found in various mitochondrial disorders (2-5). ND3 mutations were identified in patients with severe early-onset encephalopathy, Leigh syndrome, and progressive neurologic deterioration (6-8).

Here we report a novel heteroplasmic m.10197G $>$ A mutation in the ND3 gene in three Korean children with bilateral basal ganglia lesions and partial deficiencies of respiratory chain complex I activity. These findings reinforce the concept that the protein-coding mtDNA genes are important causes of complex I deficiency in diverse mitochondrial syndromes.

\section{PATIENTS AND METHODS}

Informed consent was obtained from the parents of each patient for the clinical studies including tissue and blood sampling. The patient's tissues were studied under a Columbia University Institutional Review Board protocol.

Patient 1. This 9-y-old girl was born at full term without complications. She was healthy until age $7 \mathrm{y}$ when she developed right-hand weakness and emotional lability followed by progressive gait ataxia, dystonia, poor coordination, and dysarthria. On examination, she had a normal mental status, hyperactive tendon

Received August 29, 2006; accepted December 13, 2006.

Correspondence: Michio Hirano, M.D., 630 West 168th Street, P\&S 4-443, New York, NY 10032; e-mail: mh29@ columbia.edu

This work was supported by the Korea Research Foundation Grant (KRF-2005E00024) and by grants from the National Institutes of Health (P01NS11766), Muscular Dystrophy Association, and Marriott Mitochondrial Disorders Clinical Research Fund.

DOI: $10.1203 /$ pdr.0b013e3180459f2d reflexes with ankle clonus, and cerebellar ataxia. Her venous lactate level was normal $(1.5 \mathrm{mM}$, normal $<2.5)$. There were no abnormalities in copper metabolism including serum and urine copper levels and serum ceruloplasmin level. Urine and serum amino acid and organic acid analysis were also normal. Her parents are healthy, but her older brother (patient 2) had similar symptoms. Magnetic resonance imaging (MRI) of her brain revealed increased signal intensities in both globus pallidi (Fig. 1A). A muscle biopsy specimen showed moderate subsarcolemmal proliferation of mitochondria by succinate dehydrogenase (SDH) and cytochrome $c$ oxidase (COX) histochemical stains and strongly SDH-positive blood vessels (Fig. 2A). No COX-deficient fibers were seen (Fig. 3).

Patient 2. The older brother of patient 1, patient 2 was normal until age $4 \mathrm{y}$ when he began to walk on his toes. His gait abnormality worsened, and he developed dysarthria, impaired fine motor coordination, and dystonia. He became increasingly ataxic and fell frequently. His tone was increased in all four limbs, with hyperactive tendon reflexes. His cognitive function was unaffected, and he was able to describe his symptoms well. His lactate level was borderline high (2.5 $\mathrm{mM}$, normal $<2.5$ ). Serum and urine copper levels and serum ceruloplasmin level were normal, and there were no abnormalities on other metabolic screenings. His brain MRI was similar to that of his sister (Fig. 1B). On muscle histology, ragged-red fibers and COX-deficient fibers were absent, but SDH and COX histochemistry showed mild subsarcolemmal proliferation of mitochondria.

Patient 3. He was born at full term with normal spontaneous uneventful delivery. At age 3 mo, he developed sudden left-sided weakness without cognitive changes. The left-sided weakness progressed slowly. At age 6 mo, he was evaluated at the Seoul National University Children's Hospital. Lactate levels were elevated in venous blood $(22.3 \mathrm{mg} / \mathrm{dL}$, normal $<12.5)$ and normal in cerebrospinal fluid $(2.3 \mathrm{mM}$, normal $<2.5)$. There were no abnormalities in other metabolic screenings. His brain MRI showed abnormal high signal intensities in both basal ganglia and midbrain, more prominent on right side (Fig. 1C). Muscle histology demonstrated mild mitochondrial proliferations in some fibers on SDH (Fig. 2B) and COX staining without COX-deficient fibers. With physical therapy for $1 \mathrm{y}$, his left-sided weakness improved slowly.

Biochemistry. Activities of respiratory chain enzyme complexes were measured in a supernatant from muscle homogenates and expressed relative to the activity of the citrate synthase, a marker of mitochondrial mass as described (9).

Mitochondrial DNA analyses. Total DNA was extracted from muscle homogenates (PUREGENE, Gentra Systems, Inc., Minneapolis, MN). Direct sequencing of the $N D$ genes was performed with the BigDye terminator cycle sequencing methodology on an ABI PRISM 310 Genetic Analysis (Applied Biosystems, Foster City, CA). The m.10197G $>$ A mutation was further investigated by PCR-RFLP analysis, using mismatch primers to introduce recognition sites for the restriction endonuclease $P m I$. Oligonucleotide primers forward 5'-GAGGGTTCTACTCTTTTAGT and reverse 5-AGAAGAATTTTATGGAGAAAGGGACGC $\boldsymbol{A C}$ GAGG (mismatch nucleotide shown in bold italics) amplified a 245-bp DNA fragment. The relative proportion of wild-type and mutant mtDNA was determined by last-cycle hot PCR-RFLP analysis (6). The m.10197G $>$ A transition creates a PmII site, cutting the 245-bp fragments into 215-bp and 30-bp segments.

\section{RESULTS}

Biochemical assays of mitochondrial respiratory chain activities in muscle tissue homogenates from these three patients

Abbreviations: COX, cytochrome $c$ oxidase; mtDNA, mitochondrial DNA; ND3, NADH dehydrogenase subunit 3; SDH, succinate dehydrogenase; SSV, strongly SDH-positive blood vessel 

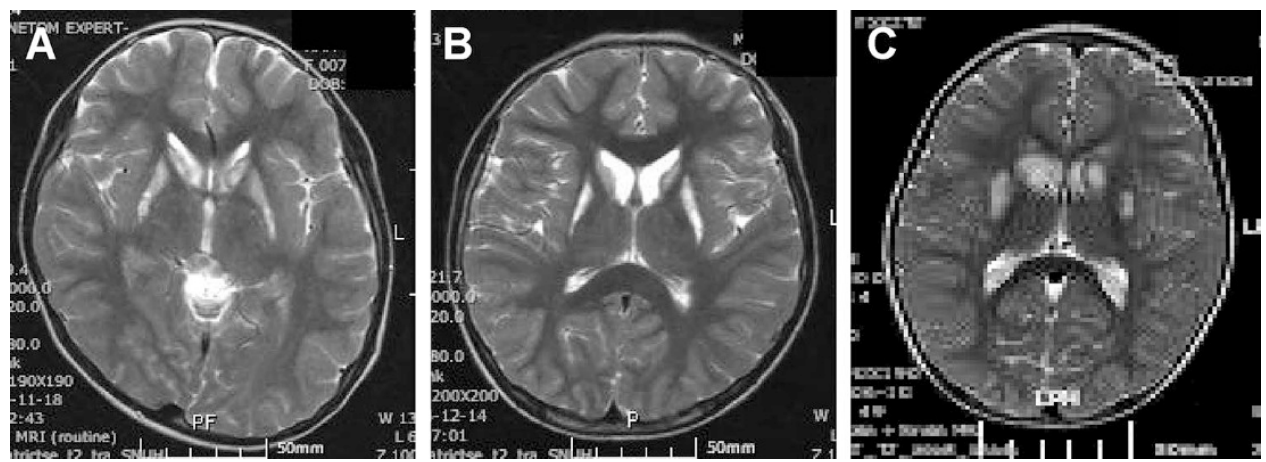

Figure 1. Brain MRI findings of three patients. Patient $1(A)$ and patient $2(B)$ showed similar abnormalities in both basal ganglia. (C) Patient 3 showed abnormal signal intensities in both basal ganglia and midbrain more prominent on right side.

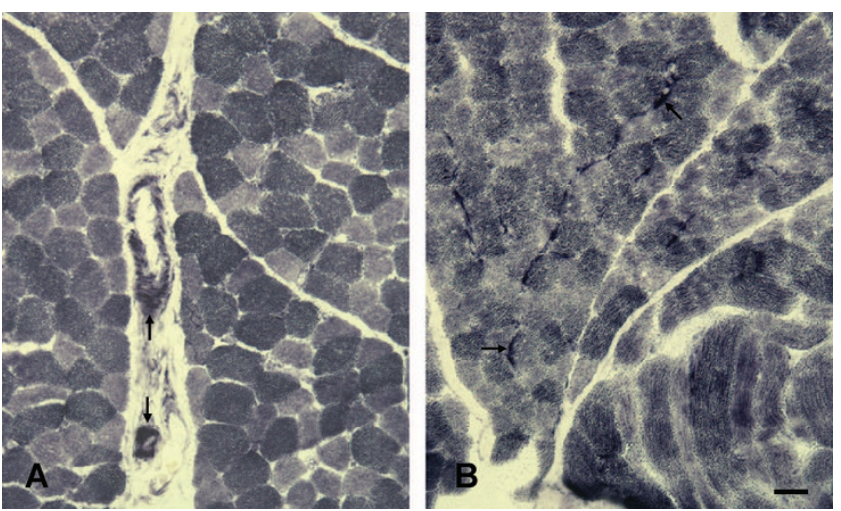

Figure 2. SDH histochemistry of muscle biopsy specimens. (A) Muscle biopsy specimen of patient 1 shows strongly SDH-positive blood vessels (SSVs) (arrows). (B) Muscle biopsy specimen of patient 3 shows focal collections of subsarcolemmal mitochondria in some muscle fibers (arrows). Bar $=50 \mu \mathrm{M}$.
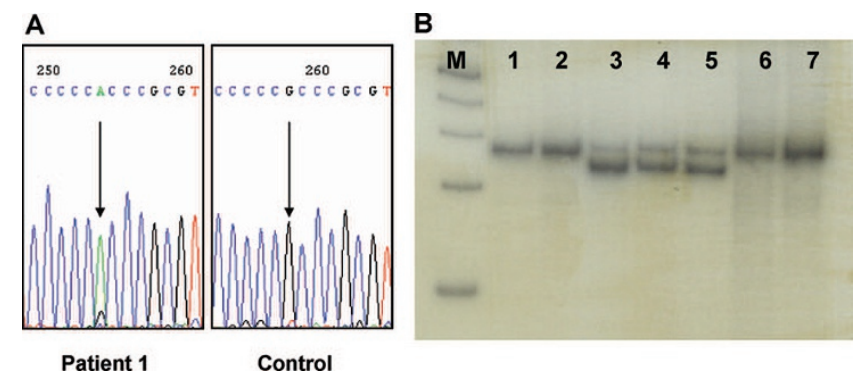

Figure 3. (A) Sequences of ND3 gene showing heteroplasmic change in patient 1 and a control. (B) Mismatch polymerase chain reaction (PCR) and restriction fragment length polymorphism (RFLP) analysis of mtDNA in the three probands, the parents of patient 3 , and a control. Lane 1, uncut 245-bp PCR product; lane 2, normal control muscle DNA; lane 3, patient 1 muscle DNA; lane 4, patient 2 muscle DNA; lane 5, patient 3 muscle DNA; lane 6, blood DNA of the mother of patient 3; lane 7, blood DNA of the father of patient 3; and lane M, 100-bp DNA ladder.

showed partial reductions of complex I activities (Table 1). Genetic screening for mtDNA rearrangements and tRNA mutations were negative. We sequenced ND coding regions of the patients' mtDNA and identified several nucleotide variants, which were previously reported as polymorphisms (patients 1 and 2: m.3618T $>\mathrm{C}, \mathrm{m} .10873 \mathrm{~T}>\mathrm{C}, \mathrm{m} .11864 \mathrm{~T}>\mathrm{C}$, m.12810A $>$ G, m.13359G $>$ C, and m13620T $>$ C; and patient 3: m.11719G $>\mathrm{A}, 12705 \mathrm{C}>\mathrm{T}, \mathrm{m} .14062 \mathrm{~A}>\mathrm{G}$, and m. $14067 \mathrm{C}>\mathrm{T}$ ), but one nucleotide transition, $\mathrm{m} .10197 \mathrm{G}>\mathrm{A}$ in ND3 has not been described. This change changes amino acid 47 from alanine to theonine and was heteroplasmic with
Table 1. Respiratory chain enzyme activities in muscle homogenates of patients normalized to citrate synthase

\begin{tabular}{lcccc}
\hline $\begin{array}{c}\text { RC enzyme } \\
\text { activities }\end{array}$ & Normal control & Patient 1 & Patient 2 & Patient 3 \\
\hline C I/CS & $0.164 \pm 0.013$ & $\mathbf{0 . 0 9 1}$ & $\mathbf{0 . 0 7 4}$ & $\mathbf{0 . 0 5 4}$ \\
C II/CS & $0.101 \pm 0.053$ & 0.064 & 0.049 & 0.07 \\
C I + III/CS & $0.103 \pm 0.038$ & $\mathbf{0 . 0 1 2}$ & $\mathbf{0 . 0 2 6}$ & $\mathbf{0 . 0 3 3}$ \\
C II + III/CS & $0.07 \pm 0.02$ & 0.045 & 0.039 & 0.04 \\
C IV/CS & $0.283 \pm 0.053$ & 0.17 & 0.17 & 0.16 \\
\hline
\end{tabular}

Abnormal values are shown in bold type. Control values are means \pm standard deviations. RC, respiratory chain; C I, complex I; C II, complex II; C III, complex III; C IV, complex IV; CS, citrate synthase.

Table 2. Multiple sequence alignment of the ND3 protein segment containing the mutation

\begin{tabular}{ll} 
Patient & TPYECGFDPMSP T RVPFSMKFFLVA \\
Human & TPYECGFDPMSP A RVPFSMKFFLVA \\
Chicken & SPYECGFDPLGS A RLPFSIRFFLVA \\
Opossum & SPYECGFDPLGS A RLPFSMKFFLVA \\
Finback whale & SPYECGFDPMGS A RLPFSMKFFLVA \\
House mouse & NPYECGFDPTSS A RLPFSMKFFLVA \\
Pisaster ochraceus & SPYECGFDPLNS A RVPFSFRFFLVAI \\
Common honey bee & SPFECGFNPITK A NLPFSLPFFLMTM \\
Escherichia coli & VPFESGIDSVGS A RLRLSAKFYLVAM \\
\hline
\end{tabular}

a level of $98 \%$ in patient $1,86 \%$ in patient 2 , and $80 \%$ in patient 3 by PCR-RFLP analysis (Fig. 2). The parents of patients 1 and 2 declined further investigation. The mutation was not detected in the blood of the mother of patient 3 . This amino acid is highly conserved across different species (Table 2). This mutation was not found in 100 control muscle DNA samples (59 healthy and 41 neuromuscular patients).

\section{DISCUSSION}

Interest in mitochondrial diseases has been shifted from mtDNA to nuclear DNA, particularly in children, in part because a larger number of nuclear than mitochondrial genes are required for mitochondrial functions (10). Nevertheless, since the identification of the first point mutation of mtDNA in a protein-coding gene (1), the number of mutations in mtDNA genes encoding structural respiratory chain subunit has gradually increased.

We identified partial deficiencies of complex I in two siblings with childhood-onset dystonia, and another child with a strokelike episode in early infancy and bilateral basal ganglia lesions. Isolated complex I deficiency, the most frequent respiratory chain disorder in infants and children, is genetically and clinically heterogeneous. Mutations in seven 
mtDNA and nine nuclear genes encoding structural subunits have been associated with complex I deficiency and their clinical phenotypes have varied from severe encephalopathies such as Leigh syndrome to neonatal cardiomyopathy (11). The clinical phenotype of our two families differed; one had childhood-onset dystonia without cognitive impairment and the other had a solitary stroke; both are unusual clinical presentation of isolated complex I deficiency. There have been a few reports of patients with dystonia due to mitochondrial disorders, especially associated with complex I deficiency (12-14), but most of the patients also had deafness, cognitive impairment, or optic neuropathy. Generalized dystonia without cognitive impairment, as in our patients 1 and 2, was an uncommon clinical presentation. Considering the frequency of multiorgan involvement in mitochondrial disorders, we need to monitor carefully our patients for other organ involvement.

Despite the mild muscle morphologic findings and normal venous lactates, biochemical assay of respiratory chain enzyme revealed decreased activity of complex I. Based on the biochemical abnormalities, we performed direct sequencing of mtDNAencoding complex I subunits and identified a novel m.10197G $>$ A heteroplasmic mutation in ND3, which is probably a pathogenic mutation based on the following lines of evidence: (1) the transition is heteroplasmic at high levels in postmitotic tissue (skeletal muscle); (2) it presented with similar encephalopathies in siblings; (3) it causes a significant amino acid change (nonpolar to polar R group), at a site that is evolutionally highly conserved (Table 2); (4) this mutation is associated with reduced activity of respiratory chain enzyme complex I; and (5) it was not found in 100 normal and disease controls.

Interestingly, another missense mutation in ND3, m.10191T $>$ C, causes an S45P change two amino acid upstream from our patients' mutation and was reported in patients with early-onset and progressive encephalopathy $(6,15)$. This mutation in the hydrophilic loop situated between two of the three membranespanning $\alpha$-helices of ND3 was confirmed to be pathogenic by cybrid cell analysis demonstrating that the m.10191T $>$ C genotype caused severe complex I deficiency (15). The A47T mutation is likely to affect folding of ND3 and hence enzyme function via interaction with other complex I subunits (6).

Despite the nearly normal muscle pathology, mutation loads in skeletal muscle of our three patients were $\geq 80 \%$ and were associated with significant defects of complex I activity. This dissociation between morphologic and biochemical findings is not uncommon among mutations of mtDNA-coding structural respiratory chain subunits, particularly those affecting complex I and is clearly different from tRNA mutations which typically cause ragged-red and COX-deficient fibers $(16,17)$.

Defects of complex I due to mtDNA or nuclear DNA mutations may comprise the most common cause of mitochondrial disease in infants and children who present with diverse severe progressive encephalopathies including Leigh syndrome (18). In particular, there is a growing number of reports describing ND5 mutations; therefore, this gene appears to be a pathogenic hotspot in these diseases (19-21). In light of recent reports describing mutations in ND3 $(6,7,15)$, this gene could be another mtDNA hotspot for mutations in pediatric patients with diverse encephalopathies.
Classic mitochondrial syndromes are seen in only a small proportion of children investigated for mitochondrial disorders. Instead, the vast majority of children suspected of having a mitochondrial disease present like our three cases with nonspecific or unusual encephalopathies. This novel mutation in the ND3 gene also reinforces the concept that proteincoding genes in mtDNA are still significant and diagnostically challenging causes of disease in children and extensive sequencing of the mtDNA-coding region might be informative in patients with normal muscle histochemical studies.

Acknowledgments. The authors thank Hua-Bin Huang and Saba Tadesse for skillful technical assistance.

\section{REFERENCES}

1. Wallace DC, Singh G, Lott MT, Hodge JA, Schurr TG, Lezza AM, Elsas LJ 2nd, Nikoskelainen EK 1988 Mitochondrial DNA mutation associated with Leber's hereditary optic neuropathy. Science 242:1427-1430

2. Jun AS, Brown MD, Wallace DC 1994 A mitochondrial DNA mutation at nucleotide pair 14459 of the NADH dehydrogenase subunit 6 gene associated with maternally inherited Leber hereditary optic neuropathy and dystonia. Proc Natl Acad Sci USA 91:6206-6210

3. Campos Y, Martin MA, Rubio JC, Gutierrez del Olmo MC, Cabello A, Arenas J 1997 Bilateral striatal necrosis and MELAS associated with a new T3308C mutation in the mitochondrial ND1 gene. Biochem Biophys Res Commun 238:323-325

4. Santorelli FM, Tanji K, Kulikova R, Shanske S, Vilarinho L, Hays AP, DiMauro S 1997 Identification of novel mutation in the mtDNA ND5 gene associated with MELAS. Biochem Biophys Res Commun 238:326-328

5. Andreu AL, Tanji K, Bruno C, Hadjigeorgiou GM, Sue CM, Jay C, Ohnishi T, Shanske S, Bonilla E, DiMauro S 1999 Exercise intolerance due to a nonsense mutation in the mtDNA ND4 gene. Ann Neurol 45:820-823

6. Taylor RW, Singh-Kler R, Hayes CM, Smith PE, Turnbull DM 2001 Progressive mitochondrial disease resulting from novel missense mutation in the mitochondrial DNA ND3 gene. Ann Neurol 50:104-107

7. Lebon S, Chol M, Benit P, Mugnier C, Chretien D, Giurgea I, Kern I, Girardin E, Hertz-Pannier L, Lonlay P, Rotig A, Rustin P, Munnich A 2003 Recurrent de novo mitochondrial DNA mutations in respiratory chain deficiency. J Med Genet 40:896-899

8. Crimi M, Papadimitriou A, Galbiati S, Palamidou P, Fortunato F, Bordoni A, Papandreou U, Papadimitriou D, Hadjigeorgiou GM, Drogari E, Bresolin N, Comi GP 2004 A new mitochondrial DNA mutation in ND3 gene causing severe Leigh syndrome with early lethality. Pediatr Res 55:842-846

9. DiMauro S, Servidei S, Zeviani M, DiRocco M, DeVivo DC, DiDonato S, Uziel G, Berry K, Hoganson G, Johnsen SD 1987 Cytochrome c oxidase deficiency in Leigh syndrome. Ann Neurol 22:498-506

10. Thorburn DR, Sugiana C, Salemi R, Kirby DM, Worgan L, Ohtake A, Ryan MT 2004 Biochemical and molecular diagnosis of mitochondrial respiratory chain disorders. Biochim Biophys Acta 1659:121-128

11. Bugiani M, Invernizzi F, Alberio S, Briem E, Lamantea E, Carrara F, Moroni E, Farina L, Spada M, Donati MA, Uziel F, Zeviani M 2004 Clinical and molecular findings in children with complex I deficiency. Biochim Biophys Acta 1659:136-147

12. Lera G, Bhatia K, Marsden CD 1994 Dystonia as the major manifestation of Leigh's syndrome. Mov Disord 9:642-649

13. Schapira AH, Warner T, Gash MT, Cleeter MW, Marinho CF, Cooper JM 1997 Complex I function in familial and sporadic dystonia. Ann Neurol 41:556-559

14. Brown MD, Hosseini S, Steiner I, Wallace DC, Korn-Lubetzki I 2004 Complete mitochondrial DNA sequence analysis in a family with early-onset dystonia and optic atrophy. Mov Disord 19:235-237

15. McFarland R, Kirby DM, Fowler KJ, Ohtake A, Ryan MT, Amor DJ, Fletcher JM, Dixon JW, Collins FA, Turnbull DM, Taylor RW, Thorburn DR 2004 De novo mutations in the mitochondrial ND3 gene as a cause of infantile mitochondrial encephalopathy and complex I deficiency. Ann Neurol 55:58-64

16. Finsterer J 2004 Mitochondriopathies. Eur J Neurol 11:163-186

17. Oldfors A, Tulinius M 2003 Mitochondrial encephalomyopathies. J Neuropathol Exp Neurol 62:217-227

18. Morris AA, Leonard JV, Brown GK, Bidouki SK, Bindoff LA, Woodward CE, Harding AE, Lake BD, Harding BN, Farrell MA, Bell JE, Mirakhur M, Turnbull DM 1996 Deficiency of respiratory chain complex I is a common cause of Leigh disease. Ann Neurol 40:25-30

19. Naini AB, Lu J, Kaufmann P, Bernstein RA, Mancuso M, Bonilla E, Hirano M, DiMauro S 2005 Novel mitochondrial DNA ND5 mutation in a patient with clinical features of MELAS and MERRF. Arch Neurol 62:473-476

20. Crimi M, Galbiati S, Moroni I, Bordoni A, Perini MP, Lamantea E, Sciacco M, Zeviani M, Biunno I, Moggio M, Scarlato G, Comi GP 2003 A missense mutation in the mitochondrial ND5 gene associated with a Leigh-MELAS overlap syndrome. Neurology 60:1857-1861

21. DiMauro S, Hirano M 2005 Mitochondrial encephalomyopathies: an update. Neuromuscul Disord 15:276-286 